\title{
Can the Covid19 pandemic affect the achievement of the 'Zero Hunger' goal? Some preliminary reflections
}

\author{
Donatella Saccone ${ }^{1}$
}

Received: 30 July 2020 / Accepted: 21 April 2021 / Published online: 2 May 2021

(c) The Author(s), under exclusive licence to Springer-Verlag GmbH Germany, part of Springer Nature 2021

\begin{abstract}
The ongoing Covid19 pandemic is producing dramatic effects on the economic and social life of many countries, which in turn may further undermine people's health and well-being. This note focuses on some potential effects on the achievement of the UN Sustainable Development Goal 2 'Zero Hunger' (Target 2.1) and, specifically, on the prevalence of undernourishment. After discussing the main changes induced by the Covid19 outbreak in various dimensions of food security, as identified by the preliminary literature on the topic, the note presents the dynamic estimates (GMM) of the recent determinants of food security, measured through the prevalence of undernourishment (SDG indicator 2.1.1), using a sample of 84 developing countries observed over the period 2000-2017. Since the rate of economic growth turns out to be a relevant determinant, the analysis quantifies the potential consequences that the economic downturn caused by the pandemic may have on the shortand long-run achievements of SDG 2 if proper counterbalancing measures will not be implemented. Such consequences in the short run would consist of millions of new undernourished people, while in the long run the progress made towards the 'Zero Hunger' goal are at risk of being completely reversed in the majority of countries. The note concludes by suggesting some directions for future research.
\end{abstract}

Keywords Covid19 pandemic $\cdot$ Food security $\cdot$ Hunger $\cdot$ Economic growth

\section{Introduction}

Signed by the 193 UN Member States as the result of an inclusive dialog among the main stakeholders involved in the process of development at various levels [10, 15, 33], the Agenda 2030 represents "a plan of action for people, planet and prosperity" [73, p. 3] calling for the achievement of 17 Sustainable Development Goals (SDGs) and 169 associated targets by 2030. Its aim is to match economic prosperity with both social inclusion and environmental protection and to purse sustainable development as a global goal. While SDG 2 'Zero Hunger' and SDG 3 'Good Health and Well-being' specifically focus on people's health, most of the other SDGs are directly or indirectly health-related [1,34].

However, when the Agenda 2030 was designed and launched in 2015, the underlying global scenario was entirely different from today. The ongoing Covid 19

Donatella Saccone

d.saccone@unisg.it

1 University of Gastronomic Sciences, Piazza Vittorio Emanuele II, 9, 12042 Bra (CN), Italy pandemic, emerged in China at the end of 2019 and rapidly spread across the globe, is producing dramatic effects on economic, social and environmental development of many countries (see, for example, Balsalobre-Lorente et al. [5]). Such effects, in turn, may not only seriously undermine the future achievement of the SDGs but also put at risk most of the recent progress towards them as well as the past progress made between 2000 and 2015 towards the Millennium Development Goals (MDGs). ${ }^{1}$ As discussed by Gulseven et al. [35], indeed, there is no SDG that is not being totally or partially affected by the Covid 19 consequences both in the short and long run. While there is an intense debate in the general and institutional media regarding such consequences, scholars are carrying out the first preliminary analyses to quantify them. In this vein, Sumner et al. [66] estimate for example that global poverty could start growing for the first time in the last 20 years, with the number of people living in poverty in 2020 increasing by 180 million

\footnotetext{
1 The MDGs were 8 goals launched by UN in 2000 and to be achieved by 2015 . They can be considered the predecessor of the SDGs. While the MDGs were all interdependent, half of them were directly related to health $(1,4,5,6)$ : https://www.un.org/millennium goals/
} 
under a scenario of a $10 \%$ global contraction. More recently, the dramatic impact of the pandemic on global poverty has been confirmed by Lakner et al. [46], who use the January 2021 forecasts from the Global Economic Prospect (World Bank) to predict an increase of the Covid19-induced new poor between 119 and 124 million in 2020. Although these are preliminary estimates based on growth forecasts, they contribute to give an idea on the size of the effects that the pandemic is having on SDGs and alert about the need for urgent counterbalancing measures.

In light of previous considerations, the present note focuses on some specific potential effects of Covid19induced changes on SDG 2 (Target 2.1), 'Zero Hunger', and aims at preliminarily anticipating their size. This aim is pursued through two steps. At first, it is indeed necessary to understand what have been the recent determinants of hunger, here defined as the prevalence of undernourishment (SDG indicator 2.1.1). ${ }^{2}$ This can help not only to anticipate the effects of the pandemic on hunger through the impact that it is having on its determinants, but also to understand which policies could counterbalance such effects. To this purpose, the extant literature provides some relevant empirical evidence which, however, presents a series of characteristics that make it not applicable to our aim (as it will be discussed in "Estimating the recent macro-determinants of undernourishment (step one)" section), among which the use of data excluding the most recent changes in global food security. We then take inspiration from Dithmer and Abdulai's conceptual framework [20], by applying it to more recent years (2000-2017), and obtain the dynamic estimates (GMM) of the macro-determinants of undernourishment in a sample of 84 developing countries, representing almost $80 \%$ of world population. Second, once the recent macro-determinants of undernourishment have been individuated, we discuss how they are being impacted by the pandemic and how, in turn, this can affect Target 2.1 of SDG 2, i.e. "ending hunger". In particular, as the rate of economic growth turns out to be one of the most relevant determinants, the estimates are used to quantify the potential impacts that the economic downturn caused by the Covid19 pandemic may have on the prevalence of undernourishment and, consequently, on the short- and long-run achievements of SDG 2. To this purpose, the growth projections provided by the IMF before and after the Covid19 emergence are employed for 2020. A similar simulation was performed at the beginning of the pandemic by Conti et al. [16] but their results were based on very early EIU's growth projections published in

\footnotetext{
$\overline{2}$ Target 2.1 is also officially measured by the prevalence of moderate or severe food insecurity in the population, based on the Food Insecurity Experience Scale. However, data are not yet available for many countries and years.
}

March 2020 and limited to a sample of net food-importing countries under the assumption of constant inequality in food consumption [31].

There are at least four reasons that justify the importance of anticipating the potential effects of the Covid19induced changes on SDG 2. First, the achievement of Goal 2 is already put under pressure by conflicts, economic slowdowns, climate change-related food crises as well as by the increase in the world population and the subsequent need of nourishing the additional 1.7 billion people who will live in the planet by 2030 [28]. In general, significant progress towards the reduction of hunger started with the end of the last century and the launch of the MDGs, with the proportion of undernourished people in developing countries falling from $23.3 \%$ in $1990-1992$ to $12.9 \%$ in 2014-2016 (UN [75]. Moreover, a comparison of data between 2000 and 2017 shows a decline in the prevalence of undernourishment in $80 \%$ of countries represented in Fig. 1. However, after decades of improvements, the absolute number of people suffering from hunger started to increase again in 2014 and, before the ongoing outbreak, 690 million people were undernourished globally [31]. Since the Covid19 pandemic could exert further pressure on the achievement of the 'Zero Hunger' goal, anticipating its impact can help to individuate proper counterbalancing measures.

Second, food systems are already being highly impacted by the ongoing pandemic and all the relevant international organizations agree on the fact that this is affecting food security at a global level. In this regard, David Beasley, the UN World Food Program Executive Director, has defined "of biblical proportions" the multiple potential famines that could emerge if effective measures are not implemented, underlying that "while dealing with a COVID-19 pandemic, we are also on the brink of a hunger pandemic". ${ }^{3}$

Third, SDG 2 is highly interconnected to the other SDGs through a series of synergies [13,25,74]. The 2019 Global Sustainable Development Report [74, p. 5] has indeed defined "building sustainable food systems and healthy nutrition patterns" as one of the six entry-points that policymakers should use to leverage these synergies and lead the transformation. This means that the impacts of the Covid19 pandemic on the achievement of SDG 2 will have in turn a domino effect on the achievement of many other SDGs and vice versa.

Finally, it seems that one of the most significant effects of recent outbreaks (Ebola, SARS and MERS) was to lead

\footnotetext{
${ }^{3}$ His intervention took place during the virtual session of the UN Security Council on the Maintenance of International Peace and Security: Protecting Civilians Affected by Conflict-Induced Hunger (April 21, 2020) and is reported here: https://www.wfp.org/news/wfpchief-warns-hunger-pandemic-covid-19-spreads-statement-un-secur ity-council
} 
Fig. 1 Prevalence of undernourishment (2000-2017)

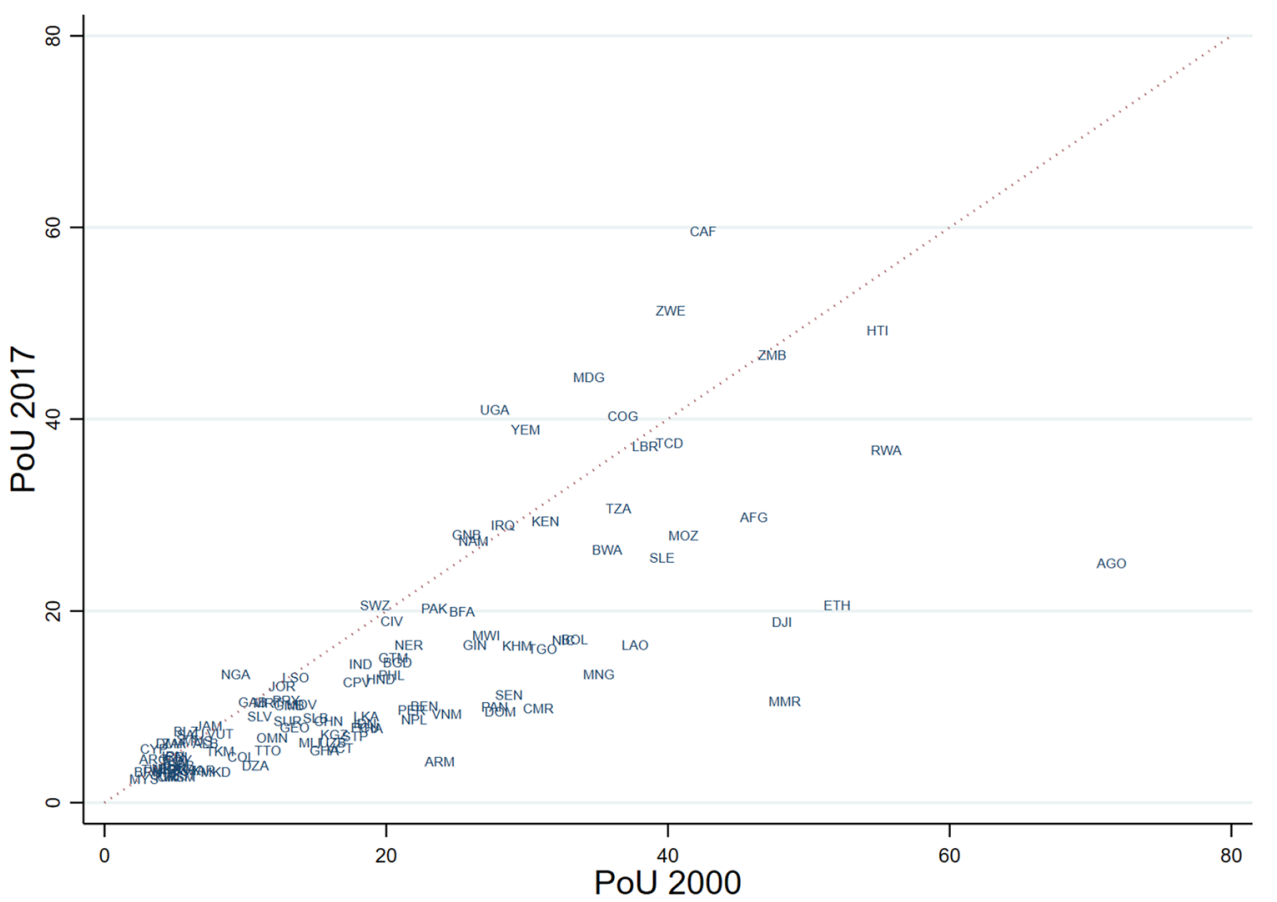

to food shortages and rapid price increases, consequently worsening the level of food security in the affected areas [23, 26, 75, 79]. For example, in 2014 the Ebola virus disease outbreak and the related movement restrictions impacted on food production, trade flows and food prices in West Africa, immediately causing food insecurity for 200,000 additional people [69]. Given the global nature of the current pandemic and the lessons learnt from previous experiences, it seems reasonable to expect analogous negative effects on the overall level of food security in most of the affected countries.

The note starts by briefly reviewing the main changes induced by the Covid19 outbreak in various dimensions of food security as identified by the preliminary literature on the topic ("How the pandemic is affecting food security: the preliminary literature" section). It then presents the dynamic estimates of the recent determinants of undernourishment ("Estimating the recent macro-determinants of undernourishment (step one)" section) and discusses how they are being impacted by the pandemic and how, in turn, this can affect the achievement of SDG 2 ("Anticipating the shortand long-run impact of the pandemic on the prevalence of undernourishment (step two)" section). Finally, "Conclusion" section concludes by pointing out policy considerations and some suggestions for future research.

\section{How the pandemic is affecting food security: the preliminary literature}

Although still limited in number, there is a growing amount of works qualitatively and quantitatively discussing the main Covid19-induced changes in various aspects related to food security (among others, [35, 37, 41, 42, 45, 47, 51, 52, 54, $58,68,81])$. Such changes, negatively affecting both supply and demand sides, concern the entire food supply chain (especially harvest, processing, trade, and logistics systems), the factor markets, the intermediate and final demand, as well as a series of macroeconomic factors, like fluctuations in exchange rates and in energy and credit markets, rise of unemployment and generalized economic contraction (for a detailed discussion about each of these changes, see [58].

Most of the above-mentioned changes, in turn, can have deep impacts on the overall degree of food security at a global level. On the one hand, trade restrictions (such as tariffs and export bans), along with the restraining measures on the national and international movements of people, are causing a decrease in food availability and access [24, 28, 29, 45, 81], and affecting food security, especially in countries most vulnerable to cereal supply shocks [72]. ${ }^{4}$ The disruptions of global chains are also limiting access to essential inputs and fertilizers, while travel restrictions have

\footnotetext{
${ }^{4}$ In particular, see FAO [28] on the impact of Covid19 on migrant workers employed in agriculture, while on the impact of current trade restrictions on agri-food markets see FAO [29].
} 
caused labor shortages, with fields that remain unplanted and unharvested, and a consequent decline in agricultural productivity [52, 63]. On the other hand, economic recession and the resulting job and income losses are affecting income distribution, people's purchasing power and, consequently, their economic access to food [67]. Particularly discussed are indeed the effects that the pandemic is having on income inequalities. While Deaton [17] shows that income inequalities between countries are not worsening, there is consensus that inequality within countries is increasing and that such effect could persist over time unless redistributive policies will be implemented [40,64]. This is also suggested by the analysis carried out by Furceri et al. [32] on the consequences of past epidemics, which are proven to be related to persistent and significant increases in inequalities.

Less certain is the impact of these changes on food and non-food prices, which can have, respectively, direct and indirect effects on the economic access to food [24]. Initially, it seemed that, while some increases in food and non-food prices occurred at the retail and local level [19], the decreasing food demand was reflected in a drop in most commodity prices ([14, 41], and World Bank data). However, ILO's estimates highlight how the food component of the Consumer Price Index has started soon to increase globally at a much faster rate than the overall Index, with the prices of food production being $5.5 \%$ higher than one year before as observed in August $2020[55,65] .{ }^{5}$ This trend is confirmed by analyzing the FAO Food Price Index, which tracks monthly changes in international prices of the most globally traded food commodities. In February 2021, the Index rose for the ninth consecutive month and reached its highest level since July $2014 .{ }^{6}$ Conversely, when observing trends in broader indexes there is no clear evidence of inflation [21], with the medium-long-term impact of the pandemic on food and non-food prices depending on a mix of different factors, such as the demand and supply adjustments as well as the future macroeconomic policies.

The first available projections of the potential changes in food security caused by the Covid19 pandemic are alarming. Some studies focus on the negative effects on specific countries or regions $[18,22,43,44,50]$. More broadly, in a preliminary technical note published by FAO, Conti et al. [16] use GMM estimates for the 1995-2017 period and predict the global per capita food supply reduction in 2020 under three hypothetical scenarios of GDP growth in net

\footnotetext{
5 IFPRI's Food Security Portal publishes the COVID-19 Food Price Monitor for South Asia and Africa, which supervises the evolution of food prices since the start of the pandemic. It is available here: http:// tools.foodsecurityportal.org/COVID-19-food-price-monitoring

${ }^{6}$ Official data and related comments are available at http://www.fao. org/worldfoodsituation/foodpricesindex/en/
}

food-importing countries, based on current EIU forecasts on GDP. By employing the 2018 coefficients of variation for representing inequality in food consumption, the authors then compute the impact of the estimated per capita food supply reduction on the prevalence of undernourishment in 2020 and predict an additional 14.4 million people in the ranks of the undernourished under the optimistic scenario, with consequences even more severe under the other two less-optimistic scenarios. ${ }^{7}$

However FAO's projections, by applying constant coefficients of variation, assume that the pandemic has no impact on inequality in food consumption within countries and only capture the Covid19 effect on the prevalence of undernourishment that occurs through changes in per capita food supply [31]. Moreover, results are limited to net food-importing countries and are only applied to the short run. Conversely, the present note provides direct estimates of the recent determinants of the prevalence of undernourishment, which is implicitly based on variation of both average food consumption and its distribution, in a sample of food-importing and exporting countries (step one), with the final purpose of anticipating and quantifying some of the potential short- and long-run impacts of the Covid19 pandemic on the achievement of SDG 2 (step two).

\section{Estimating the recent macro-determinants of undernourishment (step one)}

\section{Methodology and data}

Since many years scholars have provided extensive evidence on the determinants of food security at the micro level (see, for example, [4, 6-9, 12, 36]). From a macro perspective, instead, most literature focuses on child malnutrition rather than on the overall level of food security (see [48], for a review). For example, in a very comprehensive study, Smith and Haddad [59,60] discuss and estimate the main factors explaining child malnutrition in a sample of 63 developing countries in the period 1970-1996, finding that economic growth, health environment quality, women's education and status, national food availability, and democracy are important determinants of child malnutrition.

Conversely, the recent literature on the determinants of the overall level of food security from a macro perspective is scarce and fragmented. Soriano and Garrido [61],

\footnotetext{
7 The estimates of the impact of food supply reduction on the prevalence of undernourishment are obtained using a calculator developed by the FAO Statistic Division under the assumption that the changes in food supply are reflected in changes in the average dietary energy consumption.
} 
by analyzing a sample of 27 developing countries over the period 1991-2012, investigate the factors contributing to reducing undernutrition and find that both annual and longterm economic growth, along with improved access to basic services, are important factors. However, the authors only focus on the positive changes in the percentage of nourished population, while negative changes are not considered by the analysis. Also Dithmer and Abdulai [20] and Mary [49] provide some relevant cross-country evidence on the macrodeterminants of the overall level of food security, respectively covering periods $1980-2007$ and $1990-2013 .{ }^{8}$ Unfortunately, their results cannot be used for the final purpose of this note, i.e. for step two: Dithmer and Abdulai [20] measure food security through the average calories consumed (not included in the set of indicators for SDG 2), ${ }^{9}$ while Mary [49] adopts an estimation approach that does not fully capture long-term dynamics. Moreover, all the above-mentioned studies do not cover the most recent changes in food security that occurred over the first years of implementation of the Agenda 2030, including the increase in the number of undernourished people recorded since 2014.

The present analysis, then, takes inspiration from these works and, particularly, from Dithmer and Abdulai [20] to re-estimate the dynamic contribution of a series of macrodeterminants to the overall level of food security, measured as the prevalence of undernourishment (SDG indicator 2.1.1), in a sample of 84 developing countries observed over the period 2000-2017 for a total of 851 observations. Given the limitations of existing data sources, the sample size and the time coverage depend on data availability. The possibility of extending the analyzed period to also cover the pre-2000 years is impeded by the reliability of data on the prevalence of undernourishment. With the definition of the Agenda 2030 and the related indicators, FAO slightly changed the methodology used to measure undernourishment and, since then, the pre-2000 values are no longer reported because of some discrepancies with current data

\footnotetext{
${ }^{8}$ While both works mainly aim at estimating the effect of trade openness, they also provide estimates on other potential determinants of food security that are used as control variables.

9 As Mary [49] and Candelise et al. [13] underline, average calories consumed do not take into account distributional issues. Also the prevalence of undernourishment (PoU), as provided by FAO, is based on average calories consumed but it also accounts for inequality in food consumption by employing a coefficient of variation based on income stratifications (as reflected in national surveys). While the methodology adopted for calculating PoU is not exempt from criticisms, as largely discussed by Soriano and Garrido [61], it has been extensively used in the empirical literature as it represents an effort to also consider distributional issues and, more important, as it has been adopted for monitoring both MDG and SDG achievements [13, 49, 61, 71]. For these reasons, although its shortcomings, it seems particularly suitable for the purpose of this paper that is directly linked to monitor progress towards SDG 2.
}

[30]. For the present note, an indirect advantage of that is to limit the analysis to the MDG and early SDG era.

Analogously to Dithmer and Abdulai [20], the analysis adopts a dynamic representation of the model, which takes the form:

$\mathrm{FS}_{i, t}=\alpha+\beta \mathrm{FS}_{i, t-1}+\gamma X_{i, t}+\vartheta_{i}+u_{t}+\varepsilon_{i, t}$,

where $\mathrm{FS}_{i, t}$ represents the prevalence of undernourishment; $X_{i, t}$ is a vector comprising the main potential determinants of food security, as pointed out by the related theoretical and empirical literature $[49,59,61,70,77]$ and well-synthesized in the conceptual framework presented by Dithmer and Abdulai [20], $\vartheta_{i}$ is a time-invariant countryspecific effect, $u_{t}$ are year dummies, and $\varepsilon_{i, t}$ denotes the error term. Time dummies are included to prevent cross-individual contemporaneous correlation [56]. As the data on the prevalence of undernourishment are reported as three-year moving averages (FAOSTAT data), also the other variables in the model are transformed into three-year moving averages for the sake of conformity.

The convenience of adopting a dynamic representation of food security has been abundantly discussed and motivated by Dithmer and Abdulai [20]. In general, it allows for (a) estimating long-term dynamics when the underlying process is persistent into the future, (b) dealing with potential endogeneity and reverse causality issues. Given the dynamic nature of the model and the potential endogeneity of many regressors, the analysis employs the System GMM estimator $[3,11]$ with Windmeijer [80] finite-sample correction. While the robustness of results is checked when the one-step GMM estimator is used as an alternative, the two-step variant is preferred. The two-step procedure indeed improves the efficiency of the GMM estimator by using an optimal weighting matrix $[56,57]$. Moreover, the System GMM estimator is preferred to the Difference-GMM estimator because of its better performance in panels with small $\mathrm{N}$ and highly or moderately persistent data $[11,62]$.

The AR2 test [2] is used to exclude autocorrelation of order 2, the Hansen [39] statistics test the validity of overidentifying restrictions, finally, the Diff-Hansen test is employed to verify the exogeneity of instruments in the level equation. Since System-GMM is severely affected when the number of instruments is large compared to the number of cross sectional units, the potential proliferation bias is attenuated by employing a version of the system GMM that collapses the GMM-style instruments [56, 57]. Moreover, where necessary, the number of instruments is further reduced by dropping deeper lags if the instruments count exceeds the number of countries, so that the number of instruments is always kept below the number of units. This restriction does not affect the properties of the estimator when the number of cross sectional units is too small to 
exploit the full set of instruments [62]. Conversely, unreported attempts of estimating system GMM with the full set of instruments were affected by the proliferation bias (suggested by $p$ values of Hansen statistics collapsing to one).

The conceptual framework for the choice of the set of regressors is largely based on Dithmer and Abdulai [20], with the addition of Gini index. Income inequality, indeed, may impede an equitable access to food and be more relevant than average income in determining food security, as recently pointed out by Candelise et al. [13]. Moreover, the preliminary literature on the effects of the pandemic converges on the fact that it is having persistent impacts on income distribution $[40,64]$ and, then, it is worthy verifying whether it can potentially affect hunger.

Initially, only the main determinants of food security that are being globally affected by the Covid19 outbreak, as discussed in "How the pandemic is affecting food security: the preliminary literature" section, are included (Model 1 , Table 1). This will allow to understand if and how the pandemic - through its effects on income and its distribution, prices, agricultural productivity and trade-is also impacting on hunger. Such determinants are: real GDP per capita and its growth rate, to represent average income and how its changes affect food security through economic access to food; Gini index as a measure of income inequality; Consumer Price Index inflation rate, whose increase is supposed to be detrimental to macroeconomic stability and food access, positively impacting on the prevalence of undernourishment; agricultural productivity (measured by cereal yields), reflecting physical productivity of agriculture and expected to be negatively related to hunger; food trade openness (sum of food exports and imports divided by the value of food production), whose relation with food security is of uncertain direction and still debated by the empirical literature [49].

A set of control variables is then added (Model 2, Table 1), comprising: rural population (as a share of total population), that is a proxy for countries' structural characteristics and the relative importance of the agricultural sector; population growth, assuming that demographic pressure can affect per capita food availability and increase the prevalence of undernourishment; arable land, as a percentage of total land area, which measures the agricultural potential of a country; the percentage of people affected by natural disasters in total population and a variable measuring the occurrence of conflicts (major episodes of political violence), both expected to increase the prevalence of undernourishment. Natural disasters are treated as strictly exogenous, while all the other regressors enter the model as predetermined variables that are not strictly exogenous. Real GDP per capita and its rate of growth, Gini coefficient, CPI inflation rate, cereal yields (kg per hectare), the share of rural population, population growth and arable land are all taken from the World Development Indicators (World Bank); food exports and imports, the value of food production (to calculate food trade openness), and political stability and absence of violence/terrorism are based on FAOSTAT (FAO). The incidence of natural disasters is taken from EMDAT (CRED).

Conceptually, the relations between the prevalence of undernourishment and its determinants can be characterized by non-linearities $[20,49]$. To empirically verify whether such relations are better modeled as linear or non-linear in our data, the Ramsey test [53] and a graphical analysis of residuals, which are alternatively plotted against each explanatory variable and the predicted values, have been employed. The presence of omitted non-linearities does not clearly emerge across the different specifications, so that the 'linear-linear' form is initially preferred.

\section{Results}

Table 1 reports the estimated coefficients and the results of related tests. The AR2 tests [2] and the Hansen [39] statistics support instrument validity in all cases, while the Difference-in-Hansen tests on the exogeneity of instruments in the level equation do not permit to reject such hypothesis at any conventional level of significance. Coherently with Dithmer and Abdulai [20], the coefficient of the lagged dependent variable is significant, and its magnitude confirms the high persistence in the prevalence of undernourishment over time.

As regards the recent determinants of food security affected by the current outbreak (and discussed in "How the pandemic is affecting food security: the preliminary literature" section), three of them-economic growth, income distribution and inflation - turn out to be statistically significant across all the different specifications. The coefficients of the three variables indeed maintain their significance also when the control variables are added to the reduced model (Model 2) and these results are generally in line with the findings of previous research $[13,16,20,61] .{ }^{10}$ In addition, the relevance of the rate of economic growth was also recently highlighted by the 2020 Global Report on Food Crises [27], which points out the growing influence of economic downturns on the global levels of food insecurity (contributing to increase undernourishment in 65 out of 77 countries between 2011 and 2017).

\footnotetext{
10 The low significance of some of the other determinants, pointed out as relevant by the existing literature, is probably due to the dynamic specification of the model and the high persistence in the series. The inclusion of the lagged dependent variable may indeed subtract significance to the other regressors when its coefficient is very large.
} 
Table 1 The macro-determinants of undernourishment (alternative model specifications)

\begin{tabular}{|c|c|c|c|c|}
\hline & SYS-GMM (model 1) & SYS-GMM (model 2) & One-step SYS-GMM (model 1) & One-step SYS-GMM (model 2) \\
\hline Undernourishment $(\mathrm{t}-1)$ & $0.9804 * * *(0.0283)$ & $0.9908 * * *(0.0000)$ & $0.9840 * * *(0.0285)$ & $0.9977 * * *(0.0318)$ \\
\hline GDP per capita & $0.0001(0.0000)$ & $0.0001(0.0000)$ & $0.0001(0.0000)$ & $0.0001(0.0000)$ \\
\hline GDP growth & $-0.0871 * * *(0.0272)$ & $-0.0567 * *(0.0310)$ & $-0.1038 * * *(0.0326)$ & $-0.0702 * *(0283)$ \\
\hline Gini & $0.0938 *(0.0434)$ & $0.0521 *(0-0372)$ & $0.0964 * *(0.0379)$ & $0.0554 *(0.0306)$ \\
\hline Inflation & $0.0347 *(0.0170)$ & $0.0396 *(0.0207)$ & $0.0381 *(0.0180)$ & $0.0435^{* * * *}(0.0164)$ \\
\hline Agricultural productivity & $-0.0003 *(0.0001)$ & $-0.0001(0.0002)$ & $-0.0002 *(0.0001)$ & $-0.0001(0.0001)$ \\
\hline Food trade openness & $-0.0002(0.0001)$ & $-0.0001(0.0001)$ & $-0.0002(0.0001)$ & $-0.0001(0.0002)$ \\
\hline Rural population & & $-0.0131(0.0200)$ & & $-0.0110(0.0188)$ \\
\hline Population growth & & $0.4372 * * *(0.1396)$ & & $0.4665^{* * *}(0.1627)$ \\
\hline Arable land & & $0.0254(0.8557)$ & & $0.0312(0.0227)$ \\
\hline Natural disasters & & $0.0241(0.0240)$ & & $0.0146(0.0297)$ \\
\hline Conflicts & & $0.1867(0.1942)$ & & $0.1519(0.1501)$ \\
\hline Constant & $-4.3583 *(2.2932)$ & $-3.2926^{*}(1.5157)$ & $-4.6077 *(2.0185)$ & $-3.8856 * *(1.5858)$ \\
\hline Observations & 851 & 818 & 851 & 818 \\
\hline Number of countries & 84 & 78 & 84 & 78 \\
\hline Number of instruments & 80 & 73 & 80 & 73 \\
\hline Estimation period & $2000-2017$ & $2000-2017$ & $2000-2017$ & 2000-2017 \\
\hline AR2 test ( $p$ value) & 0.102 & 0.151 & 0.101 & 0.080 \\
\hline Hansen statistics ( $p$ value) & 0.196 & 0.205 & 0.196 & 0.205 \\
\hline Diff-Hansen ( $p$ value) & 0.132 & 0.379 & 0.132 & 0.379 \\
\hline
\end{tabular}

${ }^{* * *} p<0.01, * * p<0.05, * p<0.10$

Robust standard errors in parenthesis. Time dummies are included in all the regressions (not reported) to prevent cross-individual contemporaneous correlation [56]. The AR2 test ( $p$-value) refers to the Arellano and Bond [2] test of autocorrelation of order 2,the Hansen [39] statistics test the validity of overidentifying restrictions, the Diff-Hansen test verifies the exogeneity of instruments in the level equation (null hypothesis = exogeneity). A version of the system GMM that collapses the GMM-style instruments is employed [56, 57]. Moreover, where necessary, the number of instruments is further reduced by dropping deeper lags if the instruments count exceeds the number of countries, so that the number of instruments is always kept below the number of units

In Model 2 (Table 1, column 2), which also includes the set of control variables, the negative coefficient for economic growth reveals that a one-unit increase (decrease) in the rate of economic growth, ceteris paribus, leads to a contemporaneous decrease (increase) of 0.06 points in the percentage of undernourished people. The coefficients for inequality and inflation are both positive and suggest that the effect of a one-unit increase (decrease) in the two variables is to raise (reduce) the prevalence of undernourishment by 0.05 and 0.04 points, respectively. ${ }^{11}$ Conversely, the coefficient for agricultural productivity, initially negative and statistically significant, loses its significance when the control variables are added.

\footnotetext{
11 Also the coefficient for population growth turns out to be significant and with the expected sign. However, notwithstanding the many deaths caused by the pandemic, it seems unlikely that it will significantly change the ongoing demographic trends globally (see [78], and related audio and interviews), unless the subsequent economic uncertainty will affect birth rates in the medium-long-run.
}

\section{Anticipating the short- and long-run impact of the pandemic on the prevalence of undernourishment (step two)}

While the estimated coefficients may seem low, the dramatic changes caused by the current outbreak can have multiplicative effects ultimately leading to significant changes also in the prevalence of undernourishment at a global level. Moreover, given the high persistence in the prevalence of undernourishment, these effects can also perdure in the longrun. Unfortunately, as underlined in "How the pandemic is affecting food security: the preliminary literature" section, the Covid19 impact on general prices is barely predictable and then it is not possible, at least at this stage, to quantify its effect on the prevalence of undernourishment. Also the effects that the outbreak and its economic consequences are having on income distribution are not yet quantifiable, although a considerable increase in inequality is expected to occur globally and persist over time [40, 64]; given the significant role played by income distribution in determining 
Table 2 The effect of economic growth on the prevalence of undernourishment (alternative model specifications)

\begin{tabular}{lllll}
\hline & SYS-GMM (linear) & One-step SYS-GMM (linear) & SYS-GMM (log) & One-step SYS-GMM (log) \\
\hline Undernourishment $(t-1)$ & $0.8908^{* * *}(0.0309)$ & $0.8308^{* * *}(0.0478)$ & $0.9113^{* * *(0.0204)}$ & $0.9134 * * *(0.0224)$ \\
GDP growth & $-0.0811^{*}(0.0426)$ & $-0.1169^{* *}(0.0554)$ & $-3.4735^{* * *}(0.8871)$ & $-3.8402^{* * *}(0.8746)$ \\
Constant & $1.3316^{*}(0.6901)$ & $2.6691^{* * *}(0.9401)$ & $11.9216^{* * *}(2.7838)$ & $13.2061 * * *(2.7859)$ \\
Observations & 851 & 851 & 851 & 851 \\
Number of countries & 84 & 84 & 84 & 84 \\
Number of instruments & 52 & 52 & 52 & 52 \\
Estimation period & $2000-17$ & $2000-17$ & $2000-17$ & $2000-17$ \\
AR2 test $(p$ value $)$ & 0.630 & 0.430 & 0.659 & 0.695 \\
Hansen statistics $(p$ value $)$ & 0.221 & 0.221 & 0.067 & 0.084 \\
Diff-Hansen $(p$ value $)$ & 0.369 & 0.369 & 0.327 & 0.327 \\
\hline
\end{tabular}

${ }^{* * *} p<0.01, * * p<0.05, * p<0.10$

Robust standard errors in parenthesis. In columns 3 and 4 economic growth is log-transformed. Time dummies are included in all the regressions (not reported) to prevent cross-individual contemporaneous correlation [56]. A version of the system GMM that collapses the GMM-style instruments is employed $[56,57]$

food security, it seems reasonable to expect that such an increase has the potential to worsen global hunger.

Conversely, the revisions of the projected rates of growth following the emergence of the new global scenario can be somehow informative. To this purpose, the 2020 growth projections provided by the IMF before (October 2019) and after (October 2020) the Covid19 emergence are used to illustrate the short- and long-run impact that the resulting losses in terms of economic growth can have globally on hunger. For the short-run, this can be done using the coefficient of economic growth on undernourishment and calculating, ceteris paribus, the expected change in the dependent variable by employing the pre- and post-Covid growth projections. To this end, as many of the estimated determinants of hunger are not independent from economic growth and their effects also operate through it, it seems more appropriate to estimate a new dynamic model where economic growth is the only regressor. Such estimates are presented under both linear and non-linear scenarios. While indeed the tests on our sample have not univocally evidenced non-linearities, ${ }^{12}$ the ongoing pandemic represents a disruptive event where, as economic growth slows down, it may affect hunger more and more. In such a case, a linear-linear specification could then underestimate the impact of the economic downturn on the prevalence of undernourishment, while a linear-log form seems to be more suitable to represent it in out-of-sample predictions, under the assumption that higher losses in terms of economic growth have a larger

\footnotetext{
12 The Ramsey test suggests that there may be omitted non-linearities when economic growth is taken as the only regressor ( $p$ value $=0.01$ under the null hypothesis that the correct specification is linear), although it does not clearly emerge from the analysis of residuals.
}

impact. Results for both linear-linear and linear-log forms are reported in Table $2 .^{13}$

Before using the two new estimated coefficients for GDP growth (linear and $\log$ ) with a sufficient degree of confidence, however, it is necessary to test their sensitivity to the use of alternative sub-samples (Appendix Table 5), as the estimates may be affected by heterogeneity. While the GMM estimator already controls for time-invariant unobserved heterogeneity, sensitivity tests can be performed by estimating the models across different sub-regions when a minimum number of countries/observations per region are available, which, however, is not the case. As an alternative strategy, the sensitivity of estimates for both step one and step two is checked when each sub-region is alternatively excluded from the sample. Moreover, the models are also separately estimated for net food-importers and exporters ${ }^{14}$ and on different sub-samples alternatively excluding: the outliers, identified through the Hadi procedure [38]; the ten countries with the most extreme values of the dependent variable; the ten countries with the most extreme values of GDP growth. In all these cases, previous results are largely confirmed (to save space, only the estimates for the coefficient of GDP growth are reported in the table, while full results are available upon request). The coefficient for GDP growth, indeed, is always statistically significant and around 0.1 in the linear form, as it was in the full sample. Also

\footnotetext{
13 Following the common practice, in order to handle negative values of economic growth a constant value, slightly above the maximum negative value, has been added to the variable.

${ }^{14}$ In these two cases, estimates are limited to the reduced models where only economic growth is considered (step two), as the instruments count always exceeds the number of countries in the full model (step one) because of the limited size of the two sub-samples.
} 
Table 3 Impact of the Covid19 pandemic on economic growth and on the prevalence of undernourishment (out-of-sample predictions)

\begin{tabular}{|c|c|c|c|c|c|c|c|}
\hline & \multirow[t]{2}{*}{$\begin{array}{l}\text { No. of } \\
\text { countries }\end{array}$} & \multirow[t]{2}{*}{$\begin{array}{l}\text { Total popula- } \\
\text { tion (million) }\end{array}$} & \multirow[t]{2}{*}{$\begin{array}{l}\text { Average loss in economic } \\
\text { growth (percentage points) }\end{array}$} & \multicolumn{2}{|c|}{ Average change in $\mathrm{PoU}$} & \multicolumn{2}{|c|}{$\begin{array}{l}\text { Number of new under- } \\
\text { nourished (million) }\end{array}$} \\
\hline & & & & Linear & Non-linear & Linear & Non-linear \\
\hline Original sample & 84 & 5804.7 & -8.52 & 0.69 & 1.90 & 41.4 & 97.5 \\
\hline World-developing & 128 & 6418.3 & -8.43 & 0.68 & 1.76 & 44.7 & 105.0 \\
\hline World-total, of which: & 186 & 7616.2 & -8.78 & 0.71 & 1.90 & 52.3 & 123.7 \\
\hline Sub-Saharan Africa & 46 & 1115.6 & -6.95 & 0.56 & 1.34 & 5.54 & 12.6 \\
\hline East Asia and Pacific & 30 & 2300.2 & -6.41 & 0.52 & 1.46 & 9.8 & 19.4 \\
\hline South Asia & 8 & 1871.3 & -10.25 & 0.83 & 2.60 & 21.2 & 52.1 \\
\hline LAC & 33 & 611.8 & -13.14 & 1.07 & 3.10 & 4.8 & 12.6 \\
\hline MENA & 18 & 433.4 & -9.65 & 0.78 & 2.31 & 2.6 & 7.0 \\
\hline Europe and Central Asia & 49 & 915.9 & -8.49 & 0.69 & 1.64 & 6.4 & 15.5 \\
\hline North America & 2 & 368.0 & -7.71 & 0.63 & 1.45 & 2.0 & 4.4 \\
\hline
\end{tabular}

The average loss in economic growth is calculated as the mean of the difference between the post- (October 2020) and pre- (October 2019) Covid19 IMF projections on the growth of GDP per capita (WEO) within each regional or income group. The average change in the prevalence of undernourishment refers to the mean change by region or income group. Total population refers to the estimates for 2020 (WB)

when the $\log$ of economic growth is used, there is no much variability in the results, although the exclusion of outliers and extremes seems to yield a little higher elasticity. Only in the sub-sample of net food-exporting countries the coefficient slightly loses its statistical significance in the linear specification ( $p$-value $=0.17$ ), while results fully hold in the linear-log form.

Table 3 synthesizes the results obtained using the estimated coefficients of economic growth for the full sample (Table 2, columns 1 and 3) and calculating, ceteris paribus, the expected change in the dependent variable in 2020 by employing the pre- and post-Covid growth projections for each country. The loss in economic growth is computed as the difference between the post- (October 2020) and pre(October 2019) Covid19 IMF projections on the growth of GDP per capita (WEO). Initially, the predictions are only calculated for the 84 countries in the original sample, which represent almost $80 \%$ of world population. With an average loss of economic growth of about 8.5 percentage points, the pandemic may have generated 41.4 millions of new undernourished people in 2020 if compared to the pre-Covid 19 scenario; this number may further increase to 97.5 million under the hypothesis that higher losses in terms of economic growth cause a larger impact. Although methodologically less rigorous because of a higher heterogeneity, the coefficients estimated on the original sample can be applied to an extended sample of 186 countries. While this does not yield precise projections, it can anyhow give a preliminary idea about the size of the dramatic effects that the economic consequences of Covid19 pandemic can have had on hunger worldwide in 2020. This would correspond, respectively, to 52.3 and 123.7 millions of new undernourished people under the linear and non-linear scenarios, with Asian countries paying the highest price in absolute terms.

Although the IMF growth projections for 2021 are more optimistic and, accordingly, most economies should partially recover, the pandemic is still ongoing and the strength of the recovery is likely to vary significantly across countries. Moreover, the effects of the 2020 economic collapse on global hunger may perdure over time unless compensating changes will take place. To this purpose, besides the shortrun results, the GMM estimator also allows for using the coefficient of the lagged dependent variable to derive the long-run effect of each significant regressor. Every short-run effect, indeed, can generate persistent long-run changes by impacting on the contemporaneous level of undernourishment which, in turn, will determine its future values over time. Given the high persistence in the prevalence of undernourishment, the long-run coefficients for economic growth are much higher than for the short-run $(-4.22$ in the linear specification). ${ }^{15}$ This means that, without counterbalancing measures, persistent losses in terms of economic growth can give rise to even more dramatic increases in the hunger prevalence in the long run and jeopardize the past progress towards the 'Zero Hunger' goal. The growth losses that are necessary for leading the prevalence of undernourishment back to its 2000-level under the linear scenario can be estimated by dividing the positive changes in the prevalence of undernourishment recorded between 2000 and 2017 by the estimated long-run coefficient for economic growth. If such losses are compared to the projected losses in economic

\footnotetext{
15 The long-run coefficient for each regressor can be calculated as $(\gamma /$
} $(1-\beta))$ (see Eq. 1). 
Fig. 2 Countries at risk of regressing to the 2000-level in the prevalence of undernourishment (below the $45^{\circ}$ line). The projected loss in economic growth is calculated as the difference between the post- (October 2020) and pre- (October 2019) Covid19 IMF projections on the growth of GDP per capita for 2020 (WEO). The growth loss that is necessary for leading the prevalence of undernourishment back to its 2000-level is estimated by dividing the positive changes in the prevalence of undernourishment recorded between 2000 and 2017 by the estimated longrun coefficient for economic growth (linear scenario)

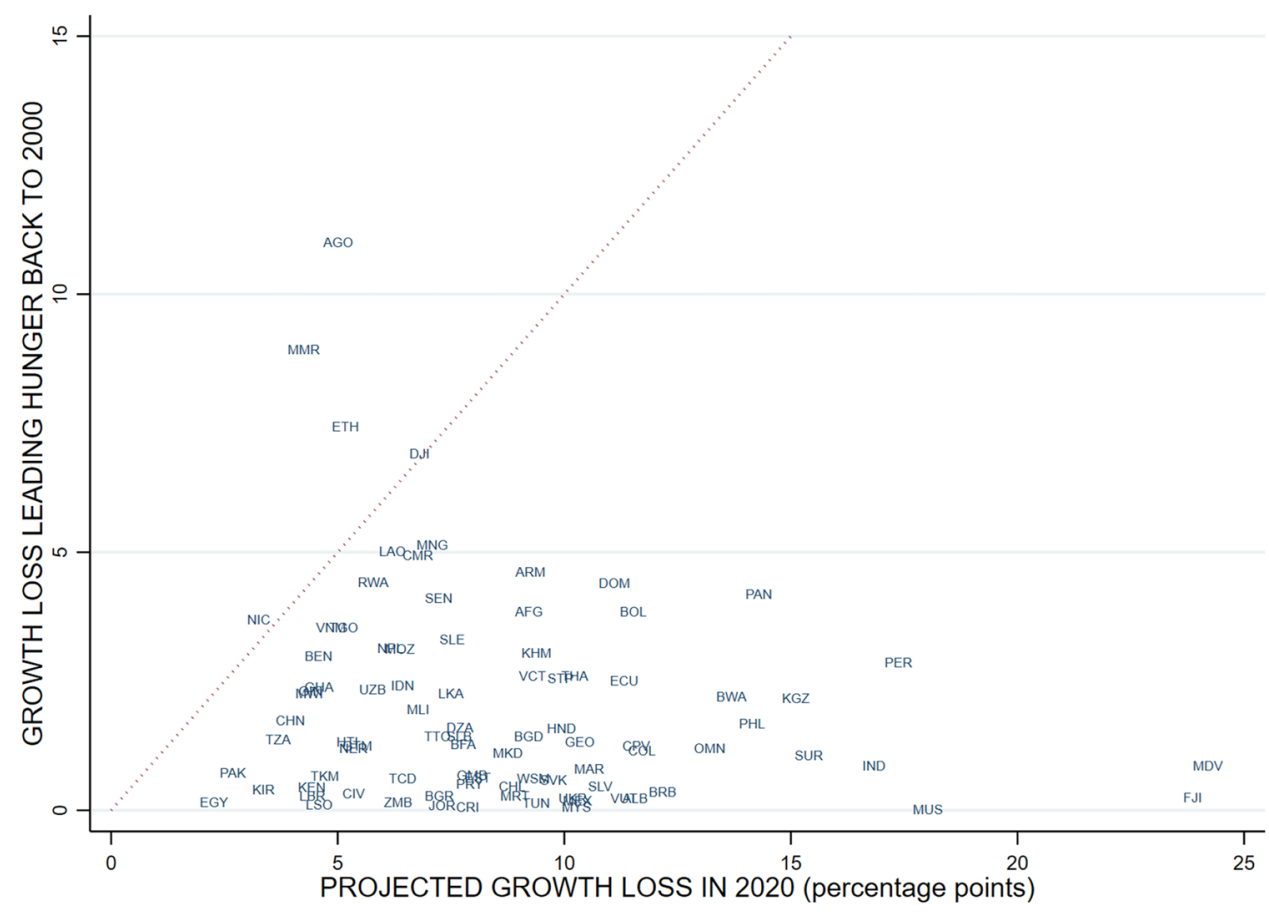

growth for 2020 (Fig. 2), it emerges that $94 \%$ of countries that recorded some improvements between 2000 and 2017 are at risk of regressing to or even exceeding such a level (countries below the $45^{\circ}$ line). Of course, such a regression can regard the totality of countries if the hypothesized nonlinearities in the effect of economic growth take place.

\section{Conclusions}

The estimates of the recent drivers of hunger show that in the new millennium the prevalence of undernourishment has been negatively related to the capacity of countries to grow, distribute income and control inflation, thus favoring people's access to food. However, as suggested by preliminary literature and data, all these aspects are being highly impacted by the ongoing pandemic. While it is not yet possible to precisely estimate how much this will ultimately affect hunger, the econometric analysis has confirmed and approximately quantified what the recent debate in the general and institutional media is extensively pointing out, i.e. that the current economic downturn can create millions of new undernourished people and further jeopardize the achievement of the 'Zero Hunger' goal.

As many relevant data are not yet available and the pandemic is still ongoing, it is important to underline that the predictions here presented are limited by a high degree of uncertainty and should be cautiously interpreted, as also specified by FAO et al. [31] in similar contexts. Nevertheless, this analysis provides a preliminary cause for reflection calling for further research refining and enlarging the scope. First of all, many other quantitative and qualitative aspects of food security that are not captured by the present study are being highly impacted by the Covid19 pandemic and require to be deeply investigated from both micro and macro perspectives. Although this analysis only focuses on the effects on the prevalence of undernourishment (SDG Target 2.1, Indicator 2.1.1), SDG 2 actually comprises 14 
different indicators measuring specific dimensions of food security whose post-Covid 19 evolution should be quantified and monitored.

Second, as data will become available, it will be important to accurately model the non-linearities that are likely to characterize the relation between food security and its determinants in periods of big discontinuity like that caused by the current outbreak. For example, as also underlined by Conti et al. [16], the elasticity of hunger may take different values in periods of growth, slowdown and recession, implying that the size of the effects may have been underestimated by the analyzed data, where dramatic decreases in GDP growth were not frequent.

Third, more research is necessary for analyzing the potential or effective impacts of the pandemic on the other SDGs within a framework that takes into account the numerous synergies and interlinkages characterizing the way towards their achievement. Finally, future research should help to identify both short- and long-run policies to respond to such impacts. The predictions for the long run, indeed, call for immediate and effective counterbalancing measures to avoid that the consequences of the pandemic will completely reverse, in most countries, the past achievements obtained during the MDG and early SGD era. To this regard, the present analysis provides some evidence in favor of policies that redistribute income and guarantee macroeconomic stability. As also underlined by Laborde et al. [45], Pereira and Oliveira [51], Swinnen and McDermott [68] from other perspectives, decreasing income inequality and supporting lower incomes are crucial actions to enhance access to food and contain the dramatic consequences of the pandemic on undernourishment. Coherently to Ebrahimy et al. [21], also appropriate policies to control temporary price spikes and inflation are necessary to protect people's purchasing power in years characterized by an exceptional degree of uncertainty.

\section{Appendix}

See Tables 4 and 5

Table 4 List of countries

\begin{tabular}{llll}
\hline Albania & Croatia & Lao PDR & Peru \\
Algeria & Cyprus & Latvia & Philippines \\
Angola & Ecuador & Lebanon & Russia \\
Armenia & Egypt & Madagascar & Senegal \\
Azerbaijan & El Salvador & Malawi & Serbia \\
Bangladesh & Estonia & Malaysia & Sierra Leone \\
Belarus & Ethiopia & Maldives & Slovak Rep \\
Benin & Fiji & Mali & South Africa \\
Bolivia & Gambia, The & Mauritius & Sri Lanka \\
Bosnia \& Herz & Ghana & Mexico & Sudan \\
Botswana & Guinea & Mongolia & Tanzania \\
Brazil & Guinea-Biss & Morocco & Thailand \\
Bulgaria & Honduras & Namibia & Timor-Leste \\
Burkina Faso & India & Nepal & Togo \\
Cameroon & Indonesia & Nicaragua & Tunisia \\
Chad & Iran & Niger & Ukraine \\
Chile & Iraq & Nigeria & Uruguay \\
China & Jordan & Macedonia & Vanuatu \\
Colombia & Kazakhstan & Pakistan & Vietnam \\
Congo, Rep & Kenya & Panama & Zambia \\
Costa Rica & Kyrgyz Rep & Paraguay & Zimbabwe \\
\hline & & &
\end{tabular}


Table 5 Robustness analysis for the SYS-GMM models

\begin{tabular}{|c|c|c|c|c|c|c|c|c|c|}
\hline Row & Change & $\begin{array}{l}\text { Coefficients } \\
\text { for GDP } \\
\text { growth }\end{array}$ & Robust se & Observations & Countries & $\begin{array}{l}\text { Number of } \\
\text { instruments }\end{array}$ & $\begin{array}{l}\text { AR2 test } \\
(p \text { value })\end{array}$ & $\begin{array}{l}\text { Hansen } \\
\text { statistics ( } p \\
\text { value) }\end{array}$ & $\begin{array}{l}\text { Diff- } \\
\text { Hansen ( } p \\
\text { value) }\end{array}$ \\
\hline \multicolumn{10}{|c|}{ Full model } \\
\hline (1) & Without outliers & $-0.1122 * * *$ & 0.0318 & 842 & 84 & 80 & 0.08 & 0.30 & 0.17 \\
\hline (2) & $\begin{array}{l}\text { Without extremes for } \\
\text { dep. variable }\end{array}$ & $-0.1176^{* * *}$ & 0.0229 & 779 & 74 & 73 & 0.10 & 0.37 & 0.46 \\
\hline (3) & $\begin{array}{l}\text { Without extremes for GDP } \\
\text { growth }\end{array}$ & $-0.1107 * * *$ & 0.0298 & 769 & 74 & 73 & 0.08 & 0.47 & 0.52 \\
\hline (4) & Without Asia & $-0.0855^{* *}$ & 0.0349 & 648 & 67 & 66 & 0.08 & 0.36 & 0.07 \\
\hline (5) & Without SSA & $-0.1292 * * *$ & 0.0299 & 644 & 56 & 52 & 0.06 & 0.19 & 0.36 \\
\hline (6) & Without LAC & $-0.0756^{*}$ & 0.0439 & 638 & 70 & 66 & 0.85 & 0.22 & 0.23 \\
\hline (7) & Without MENA & $-0.0807 * *$ & 0.0373 & 785 & 76 & 66 & 0.07 & 0.17 & 0.12 \\
\hline \multicolumn{10}{|c|}{ GDP growth only } \\
\hline (1) & Without outliers & $-0.1307 * *$ & 0.0668 & 842 & 84 & 52 & 0.53 & 0.28 & 0.13 \\
\hline (2) & $\begin{array}{l}\text { Without extremes for } \\
\text { dep. variable }\end{array}$ & $-0.1142 * *$ & 0.0474 & 779 & 74 & 52 & 0.43 & 0.18 & 0.68 \\
\hline (3) & $\begin{array}{l}\text { Without extremes for GDP } \\
\text { growth }\end{array}$ & -0.0971 & 0.0729 & 769 & 74 & 52 & 0.90 & 0.23 & 0.67 \\
\hline (4) & Without Asia & $-0.0755^{* *}$ & 0.0372 & 648 & 67 & 52 & 0.94 & 0.18 & 0.59 \\
\hline (5) & Without SSA & $-0.1336^{* * *}$ & 0.0306 & 644 & 56 & 52 & 0.56 & 0.20 & 0.48 \\
\hline (6) & Without LAC & -0.0822 & 0.0492 & 638 & 70 & 52 & 0.32 & 0.76 & 0.58 \\
\hline (7) & Without MENA & $-0.0922 * *$ & 0.0479 & 785 & 76 & 52 & 0.92 & 0.21 & 0.23 \\
\hline (8) & Net food-importers & $-0.1090 * * *$ & 0.0415 & 507 & 65 & 52 & 0.24 & 0.65 & 0.86 \\
\hline (9) & Net food-exporters & -0.0552 & 0.0407 & 344 & 36 & 33 & 0.41 & 0.48 & 0.32 \\
\hline \multicolumn{10}{|c|}{ GDP growth (log) only } \\
\hline (1) & Without outliers & $-5.4299 * * *$ & 1.1682 & 842 & 84 & 52 & 0.84 & 0.23 & 0.04 \\
\hline (2) & $\begin{array}{l}\text { Without extremes for dep. } \\
\text { variable }\end{array}$ & $-3.5927 * * *$ & 0.8943 & 779 & 74 & 52 & 0.47 & 0.16 & 0.58 \\
\hline (3) & $\begin{array}{l}\text { Without extremes for GDP } \\
\text { growth }\end{array}$ & $-4.5706^{* * *}$ & 1.1030 & 769 & 74 & 52 & 0.32 & 0.17 & 0.15 \\
\hline (4) & Without Asia & $-4.3243 * * *$ & 0.8653 & 648 & 67 & 52 & 0.98 & 0.14 & 0.07 \\
\hline$(5)$ & Without SSA & $-3.2671 * * *$ & 0.6799 & 644 & 56 & 52 & 0.66 & 0.16 & 0.72 \\
\hline (6) & Without LAC & $-3.2742 * * *$ & 0.8761 & 638 & 70 & 52 & 0.29 & 0.18 & 0.41 \\
\hline (7) & Without MENA & $-3.8252 * * *$ & 0.9370 & 785 & 76 & 52 & 0.49 & 0.08 & 0.14 \\
\hline (8) & Net food-importers & $-3.1420 * * *$ & 0.6975 & 507 & 65 & 52 & 0.54 & 0.19 & 0.22 \\
\hline (9) & Net food-exporters & $-3.0416^{* *}$ & 1.4623 & 344 & 36 & 35 & 0.55 & 0.05 & 0.35 \\
\hline
\end{tabular}

$* * * p<0.01, * * p<0.02, * p<0.05$

Time dummies are included in all the regressions. A version of the system GMM that collapses the GMM-style instruments is employed [56,57]. Moreover, where necessary, the number of instruments is further reduced by dropping deeper lags if the instruments count exceeds the number of countries, so that the number of instruments is always kept below the number of units. Full model refers to Model 1 in Table 4, which has the advantage of containing the number of regressors

\section{References}

1. Alhassan, G.N., Adedoyin, F.F., Bekun, F.V., Agabo, T.J.: Does life expectancy, death rate and public health expenditure matter in sustaining economic growth under COVID-19: empirical evidence from Nigeria?. J. Public Affairs e2302 (2020)

2. Arellano, M., Bond, S.: Some tests of specification for panel data: Monte Carlo evidence and an application to employment equations. Rev. Econ. Stud. 58, 277-297 (1991)

3. Arellano, M., Bover, O.: Another look at the instrumental variable estimation of error-components models. J. Econom. 68, 29-51 (1995)
4. Baland, J.M., Ziparo, R.: Intra-household bargaining. In: Anderson, S., Beaman, L.A., Platteau, J.-P. (eds.) Towards Gender Equity in Development. Oxford University Press, Oxford (2018)

5. Balsalobre-Lorente, D., Driha, O.M., Bekun, F.V., et al.: Consequences of COVID-19 on the social isolation of the Chinese economy: accounting for the role of reduction in carbon emissions. Air Qual. Atmos. Health 13, 1439-1451 (2020)

6. Behrman, J.R., Deolalikar, A.B.: Will developing country nutrition improve with income? A case study for rural South India. J. Polit. Econ. 95(3), 492-507 (1987) 
7. Bellemare, M.F., Novak, L.: Contract farming and food security. Am. J. Agr. Econ. 99(2), 357-378 (2017)

8. Bellemare, M.F., Barrett, C.B., Just, D.R.: The welfare impacts of commodity price volatility: evidence from rural Ethiopia. Am. J. Agr. Econ. 95(4), 877-899 (2013)

9. Berhman, J.R.: Nutrient Intake Demand Relations: Income, Prices, Schooling. Working Papers 149. Department of Economics, Williams College (1990)

10. Biggeri, M., Clark, D.A., Ferrannini, A., Mauro, V.: Tracking the SDGs in an 'integrated' manner: a proposal for a new index to capture synergies and trade-offs between and within goals. World Dev. 122, 628-647 (2019). https://doi.org/10.1016/j. worlddev.2019.05.022

11. Blundell, R., Bond, S.: Initial conditions and moment restrictions in dynamic panel data models. J. Econometr. 87, 115-143 (1998)

12. Bouis, H.E., Haddad, L.J.: Are estimates of calorie-income elasticities too high? A recalibration of the plausible range. J. Dev. Econ. 39(2), 333-364 (1992)

13. Candelise, C., Saccone, D., Vallino, E.: An empirical assessment of the effects of electricity access on food security. World Dev. 141, 105390 (2021)

14. Ceylan, R.F., Ozkan, B., Mulazimogullari, E.: Historical evidence for economic effects of COVID-19. Eur. J. Health Econ. 21, 817$823(2020)$

15. Clark, D.A., Biggeri, M., Frediani, A.: Participation, empowerment and capabilities: key lessons and future challenges. In: Clark, D.A., Biggeri, M., Frediani, A.A. (eds.) The Capability Approach, Empowerment and Participation: Concepts, Measures and Applications, pp. 385-402. Palgrave Macmillan, Basingstoke (2019)

16. Conti, V., Cafiero, C., Sánchez, M.V.: Simulating rising undernourishment during the COVID-19 pandemic economic downturn. Technical note. Rome, FAO. https://doi.org/https://doi.org/ $10.4060 / \mathrm{ca} 8815$ en $(2020)$

17. Deaton A.: COVID-19 and Global Income Inequality. Working Paper 28392. National Bureau for Economic Research, Cambridge (2021)

18. Dev S.M.: Addressing COVID-19 impacts on agriculture, food security, and livelihoods in India. In Swinnen, J., McDermott, J. (eds.) COVID-19 and Global Food Security. Part One: Food Security, Poverty, and Inequality, Chapter 7, pp. 33-35. International Food Policy Research Institute (IFPRI), Washington, DC (2020)

19. Devereux, S., Béné, C., Hoddinott, J.: Conceptualising COVID-19's impacts on household food security. Food Security 12, 769-772 (2020)

20. Dithmer, J., Abdulai, A.: Does trade openness contribute to food security? A dynamic panel analysis. Food Policy 69, 218-230 (2017)

21. Ebrahimy, E., Igan, D., Peria, M.: The impact of Covid-19 on inflation: potential drivers and dynamics. IMF Special Notes Series on Covid-19. September 10, pp. 1-14 (2020)

22. Elsahoryi, N., Al-Sayyed, H., Odeh, M., McGrattan, A., Hammad, F.: Effect of Covid-19 on food security: a cross-sectional survey. Clin. Nutr. ESPEN 40, 171-178 (2020)

23. Elston, J.W.T., Cartwright, C., Ndumbi, P., Wright, J.: The health impact of the 2014-15 Ebola outbreak. Public Health 143, 60-70 (2017)

24. Erokhin, V., Gao, T.: Impacts of COVID-19 on trade and economic aspects of food security: evidence from 45 developing countries. Int. J. Environ. Res. Public Health 17(16), 5775 (2020)

25. Fader, M., Cranmer, C., Lawford, R., Engel-Cox, J.: Toward an understanding of synergies and trade-offs between water, energy, and food SDG targets. Front. Env. Sci. November (2018)

26. FAO: Impact of the Ebola Virus Disease Outbreak on Market Chains and Trade of Agricultural Products in West Africa, June
2016. Available http://www.fao.org/emergencies/resources/docum ents/resources-detail/it/c/417072/ (2016)

27. FAO: Global Report on Food Crises 2020. Available https://www. wfp.org/publications/2020-global-report-food-crises (2020a)

28. FAO: Migrant Workers and the COVID-19 Pandemic. Rome. Available here: https://doi.org/https://doi.org/10.4060/ca8559en (2020b)

29. FAO: Agri-Food Markets and Trade in the Time of COVID-19. Rome. Available https://doi.org/https://doi.org/10.4060/ca8446en (2020c)

30. FAO: Indicator 2.1.1: Prevalence of Undernourishment-Metadata. Available http://www.fao.org/sustainable-developmentgoals/indicators/211/en/ (2020d)

31. FAO, IFAD, UNICEF, WFP and WHO: The State of Food Security and Nutrition in the World 2020. Transforming Food Systems for Affordable Healthy Diets. FAO, Rome (2020)

32. Furceri, D., Loungani, P., Ostry, J.D., Pizzuto, P.: Will Covid-19 affect inequality? Evidence from past pandemics. Covid Econ. 12, $138-157$ (2020)

33. Gasper D.: The road to the sustainable development goals: building global alliances-for more ethical development? Paper prepared for the IDEA-GRETHA 2018 Congress: A World United, Bordeaux, 25-27 June (2018)

34. GBD 2015 SDG Collaborators: Measuring the health-related Sustainable Development Goals in 188 countries: a baseline analysis from the Global Burden of Disease Study 2015. Lancet 388(10053), 1813-1850 (2016)

35. Gulseven, O., Al Harmoodi, F., Al Falasi, M., Alshomali, I.: How the COVID-19 pandemic will affect the UN sustainable development goals? (May 4, 2020). Available at SSRN https://ssrn.com/ abstract $=3592933$ or https://doi.org/10.2139/ssrn.3592933 (2020)

36. Haddad, L.J., Peña, C., Nishida, C., Quisumbing, A.R., Slack A.: Food security and nutrition implications of intrahousehold bias: a review of literature. FCND discussion paper no. 19. International Food Policy Research Institute, Washington DC (1996)

37. Haddad, L., Fanzo, J., Godfrey, S., Hawkes, C., Morris, S., Neufeld, L.: The COVID-19 crisis and food systems: addressing threats, creating opportunities. Global alliance for improved nutrition. Available https://www.gainhealth.org/media/news/covid-19crisis-and-food-systems-addressing-threats-creating-opportunities (2020)

38. Hadi, A.S.: Identifying multiple outliers in multivariate data. J. Roy. Stat. Soc. B 54(3), 761-771 (1992)

39. Hansen, L.P.: Large sample properties of generalized method of moments estimators. Econometrica 50(4), 1029-1054 (1982). https://doi.org/10.2307/1912775

40. Hill, R.V., Narayan, A.: Covid-19 and inequality: a review of the evidence on likely impact and policy options. Working paper 3, Centre for Disaster Protection. December (2020)

41. HLPE.: Impact of COVID-19 on Food Security and Nutrition (FSN). Committee on World Food Security, 9 April 2020. Available https://ec.europa.eu/knowledge4policy/publication/impactcovid-19-food-security-nutrition-fsn_en (2020)

42. IPES-FOOD: COVID-19 and the crisis in food systems: symptoms, causes, and potential solutions. Communiqué, April 2020. Available http://www.ipes-food.org/pages/covid19 (2020)

43. Kansiime, M.K., Tambo, J.A., Mugambi, I., Bundi, M., Kara, A., Owuor, C.: COVID-19 implications on household income and food security in Kenya and Uganda: findings from a rapid assessment. World Dev. 137 (2021)

44. Kundu, S., Banna, M.H.A., Sayeed, A., Sultana, M.S., Brazendale, K., Harris, J., Mandal, M., Jahan, I., Abid, M.T., Khan, M.S.I.: Determinants of household food security and dietary diversity during the COVID-19 pandemic in Bangladesh. Public Health Nutr. 15, 1-9 (2020). https://doi.org/10.1017/S13689800200050 42 
45. Laborde, D., Martin, W., Swinnen, J., Vos, R.: COVID-19 risks to global food security. Science 369(6503), 500-502 (2020)

46. Lakner, C., et al.: Updated estimates of the impact of COVID19 on global poverty: looking back at 2020 and the outlook for 2021. World Bank Blogs. January 11, 2021. Available at https:// blogs.worldbank.org/opendata/updated-estimates-impact-covid19-global-poverty-looking-back-2020-and-outlook-2021 (2021)

47. Mardones, F.O., Rich, K.M., Boden, L.A., Moreno-Switt, A.I., Caipo, M.L., Zimin-Veselkoff, N., Alateeqi, A.M., Baltenweck, I.: The COVID-19 pandemic and global food security. Front. Vet. Sci. 7, 578508 (2020)

48. Mary S.: How much does economic growth contribute to child stunting reductions? Economies 6(55) (2018). https://doi.org/10. 3390/economies6040055

49. Mary, S.: Hungry for free trade? Food trade and extreme hunger in developing countries. Food Security 11(2), 461-477 (2019)

50. Pakravan-Charvadeh, M.R., Mohammadi-Nasrabadi, F., Gholamrezai, S., Vatanparast, H., Flora, C., Nabavi-Pelesaraei, A.: The short-term effects of COVID-19 outbreak on dietary diversity and food security status of Iranian households (a case study in Tehran province). J. Clean. Prod. 281, 124537 (2021)

51. Pereira, M., Oliveira, A.M.: Poverty and food insecurity may increase as the threat of COVID-19 spreads. Public Health Nutr. 23(17), 3236-3240 (2020). https://doi.org/10.1017/S136898002 0003493

52. Poudel, P.B., et al.: COVID-19 and its global impact on food and agriculture. J. Biol. Today's World 9(5), 221-225 (2020)

53. Ramsey, J.B.: Tests for specification errors in classical linear least-squares regression analysis. J. Roy. Stat. Soc. B 31, 350371 (1969)

54. Reardon, T., Bellemare, M.F., Zilberman, D.: How COVID-19 may disrupt food supply chains in developing countries. IFPRI Blog, 2 April 2020. Available https://www.ifpri.org/blog/howcovid-19-may-disrupt-food-supply-chains-developing-countries (2020)

55. Reinsdorf, M.B.: COVID-19 and the CPI: is inflation underestimated? IMF working papers 2020/224. International Monetary Fund (2020)

56. Roodman, D.: How to do xtabond2: an introduction to difference and system GMM in Stata. Stata J. 9(1), 86-136 (2009)

57. Roodman, D.: A note on the theme of too many instruments. Oxford Bull. Econ. Stat. 71(1), 135-158 (2009)

58. Schmidhuber, J., Pound, J., Qiao, B.: COVID-19: channels of transmission to food and agriculture. FAO, Rome. https://doi. org/10.4060/ca8430en (2020)

59. Smith, L.C., Haddad, L.J.: Explaining child malnutrition in developing countries: a cross-country analysis. Research report 111. International Food Policy Research Institute (IFPRI) (2000)

60. Smith, L.C., Haddad, L.J.: How potent is economic growth in reducing undernutrition? What are the pathways of impact? New cross-country evidence. Econ. Dev. Cult. Change 51(1), 55-76 (2002)

61. Soriano, B., Garrido, A.: How important is economic growth for reducing undernourishment in developing countries? Food Policy 63, 87-101 (2016)

62. Soto, M.: System GMM estimation with a small sample. Working Papers 395, Barcelona Graduate School of Economics (2009)

63. Steensland A.: 2020 Global agricultural productivity report: productivity in a time of pandemics. In: Thompson, T. (ed.) Virginia Tech College of Agriculture and Life Sciences (2020)

64. Stiglitz J.: Conquering the great divide. IMF Fin. Dev. Fall (2020)
65. Stoevska S.: COVID-19 is driving up food prices all over the world-ILOSTAT, December 9. Available https://ilostat.ilo.org/ covid-19-is-driving-up-food-prices-all-over-the-world/ (2020)

66. Sumner, A., Hoy, C., Ortiz-Juarez, E.: Estimates of the impact of Covid-19 on global poverty. WIDER Working Paper 2020/43, Helsinki, UNU-WIDER (2020)

67. Swinnen J.: COVID-19 is exacerbating inequalities in food security. In: Swinnen, J., McDermott, J. (eds.) COVID-19 and Global Food Security, Part One: Food Security, Poverty, and Inequality, Chapter 3, pp. 20-22. International Food Policy Research Institute (IFPRI), Washington, DC. https://doi.org/10.2499/p15738coll2. 133762_03 (2020)

68. Swinnen, J., McDermott, J.: COVID-19 and Global Food Security. International Food Policy Research Institute (IFPRI), Washington, DC (2020)

69. Thomas, A.C., Nkunzimana, T., Perez, H.A., Kayitakire, F.: Impact of the West African Ebola Virus Disease Outbreak on Food security. Joint Research Centre -European Commission, Ispra, Italy (2014)

70. Timmer, C.P.: The macro dimensions of food security: economic growth, equitable distribution, and food price stability. Food Policy 25(3), 283-295 (2000)

71. Tiwari, S., Zaman, H.: The Impact of Economic Shocks on Global Undernourishment. Policy Research Working Paper 5215, The World Bank, Washington D.C. (2010)

72. Udmale, P., Pal, I., Szabo, S., Pramanik, M., Large, A.: Global food security in the context of COVID-19: a scenario-based exploratory analysis. Progr. Disaster Sci. 7, 100120 (2020)

73. UN: Transforming our world: the 2030 Agenda for Sustainable Development. Resolution adopted by the General Assembly (A/ RES/70/1), 25 September (2015)

74. UN: Global Sustainable Development Report 2019: The Future is Now-Science for Achieving Sustainable Development, United Nations (2019)

75. UN DESA: The Millennium Development Goals Report 2015. UN, New York. Availablehttps://doi.org/10.18356/6cd11401-en (2016)

76. UNDP: The economic and social impact of Ebola on households in Sierra Leone. June. Available https://www.sl.undp.org/conte nt/sierraleone/en/home/library/crisis_prevention_and_recovery/ the-economic-and-social-impact-of-ebola-on-households-in-sierr a-.html (2015)

77. UNICEF: The State of the World's Children. United Nations Children's Fund, New York (1998)

78. Vollset, S.E., et al.: Fertility, mortality, migration, and population scenarios for 195 countries and territories from 2017 to 2100 : a forecasting analysis for the Global Burden of Disease Study. Lancet 396(10258), 1285-1306 (2020)

79. WFP-World Food Programme: Ebola-Special Focus: How can we estimate the impact of Ebola on food security in Guinea, Liberia and Sierra Leone? November 2014. Available https://www. wfp.org/publications/ebola-special-focus (2014)

80. Windmeijer, F.: A finite sample correction for the variance of linear efficient two-step GMM estimators. J. Econometr. 126, 25-517 (2005)

81. Zurayk, R.: Pandemic and food security: a view from the global South. J. Agric. Food Syst. Commun. Dev. 9(3), 17-21 (2020). https://doi.org/10.5304/jafscd.2020.093.014

Publisher's Note Springer Nature remains neutral with regard to jurisdictional claims in published maps and institutional affiliations. 